\title{
NEIGHBOUR ANALYSIS FOR ADJUSTMENT FOR INTERPLOT COMPETITION
}

M. Pithuncharurnlap ${ }^{1}$, K.E. Basford ${ }^{1}$ and W.T. Federer ${ }^{2}$

1 Department of Agriculture, University of Queensland, Queensland 4072, Australia

2 Biometrics Unit, 337 Warren Hall, Cornell University, Ithaca, NY 14853-7801, USA

\section{Summary}

BU-1118-M

In field experiments involving a large number of experimental plots, a neighbour analysis can be used to control

environmental variation by estimating the trend within blocks. The effect of interplot competition is also another important source of variation which has an influence on the estimation of treatment contrasts. To reduce the effect of the variation from these sources and to improve the precision of comparison between treatments, a spatial model is proposed for incorporating trend effect and interplot competition. It is determined by a modification to the residual maximum likelihood neighbour analysis of Gleeson and Cullis (1987). Two different methods of defining interplot competition are used in this model. Real examples illustrate this methodology. The results indicated that the model which incorporated trend effect and interplot competition gave no appreciable difference in mean SED compared with the model taking into account only the trend effect. However, the ranking of estimated treatment means did differ. The significance of both the competition coefficient and trend effect are important indexes in assessing the usefulness of the model. 
Introduction

A major source of variation in a field experiment is the lack of uniformity across the field. The most common way of controlling environmental variation is appropriate use of blocking techniques. But, when a large number of treatments are to be compared in a field trial, the blocking method may be ineffective. Recently, spatial analysis has been widely discussed as an alternative method for such situations. The aim is to remove the trend effect or variation within the blocks from the treatment contrasts by using the association between neighbouring plots. Some of the major papers are Wilkinson et al. (1983), Patterson and Hunter (1983), Green et al. (1985), Williams (1986), Besag and Kempton (1986) and Gleeson and Cullis (1987). All proposed techniques are based on a 'trend + error ' model and employ, at least implicitly, some form of differencing of data to remove an assumed trend. These neighbour analyses differ in the assumptions about trend, and their methods of estimation.

An important additional source of variation is that contributed by the effects of plant competition. There is a large literature on plant competition in field experiments, and there is evidence to show that their effects can be important in some situations. Kempton (1982) found that competition effects between adjacent single row plots in sugar beet trials caused unadjusted estimates of the difference in variety means to overestimate the true difference by as much 
as 40\%. Wilkinson et al. (1983), and Besag and Kempton (1986) found that the interplot competition might cause inefficient estimation of treatment contrasts. There have also been investigations into the effects of competition on the means of each of several characteristics. Jensen and Federer (1964), and Austin and Blackwell (1980) have shown that the interplot competition can lead to biased estimates of yield when varieties differ substantially in plant height. Workers in many crops have found competition to be associated with varietal differences in tillering ability (Gomez, 1972), root size (Kempton, 1982), and canopy size (Cannell et al., 1977).

The competition effect can be eliminated most simply through additional spacing or through the use of border rows. However, this may increase the heterogeneity within blocks and increase the amount of material requiring a resource which is limiting (Federer and Basford, 1990). Another method of correcting for interplot competition effects is to measure and remove the correlation between the yield of any particular plot and the yield of its neighbouring plots.

Different authors have chosen various combinations of neighbouring plots to describe competition effects and have used different methods of estimating the correlation coefficient. Mead (1967) considered an hexagonal array with the six nearest plots as neighbours. He produced a method of estimating the correlation coefficient by transforming the observed variable to another variable which does appear to 
satisfy the assumption of normality for the estimated correlation coefficient. Kempton (1982) introduced an additional term proportional to the mean of neighbouring plots by consideredya one-dimensional array with the two nearest plots as neighbours. The mean of neighbouring plots is used as a simple covariate and maximum likelihood used to estimate competition effects.

Pearce (1957) considered a model incorporating plot interference in which the yield of a plot is assumed to have been directly influenced by the treatment effect applied to that plot and by the treatment applied to each neighbouring plot. He defined all plots from the same block to be neighbours and used ordinary least squares for the linear model to estimate competition effects. Besag and Kempton (1986) have followed Pearce's method for assessing competition effects but used the two nearest plots as neighbours. Federer and Basford (1987) took the four nearest plots to be neighbours and used the corresponding plot shape for weighting in a least squares method of estimating competition effects.

Kempton and Lockwood (1984) introduced other variables as a covariate in the model; the covariate being equal to the difference between the plot value and the mean of the two neighbouring plots. Draper and Guttman (1980) considered the competition effects on a plot to depend only on the treatment of the neighbouring plots. They fitted a non-linear model by incorporating interplot competition assuming only plots which 
are physically adjacent "horizontally, vertically or diagonally" mutually affect each other.

In this study, a spatial model for incorporating trend effect predicted from neighbouring plots and interplot competition is considered by a modification to the REMLN analysis of Gleeson and Cullis (1987). For comparison, the method proposed by Besag and Kempton (1986) and the method of using the mean of neighbouring plots as a simple covariate to assess only the competition effect are also used. The estimates of experimental error mean square and standard error of mean differences are used as criteria for determining the effectiveness of the model. The effect of trend and interplot competition on comparisons of estimated treatment means and their ranking is also investigated for these methods.

\section{Model and Estimation}

The yield of a plot is assumed to have been influenced directly by the treatment applied to it and indirectly by the treatments applied to each neighbouring plot. Under additivity of direct and neighbour treatment effects, Besag and Kempton (1986) proposed a model taking into account interplot competition or plot interference as follows:

$$
y=B \pi+T \alpha+R T \beta+\tau
$$


where $y$ is an n-vector of plot yields,

$\pi$ is a $b$-vector of block effects with incidence matrix $B$,

$T$ is the corresponding design matrix,

$\alpha$ is a $t$-vector of treatment effects,

$R$ is the neighbour incidence matrix,

$B$ is a $t$-vector of competition effects, and

$\tau$ is an $n$-vector whose elements represent local error.

If $\tau$ represents the independent error term with mean zero and variance $\sigma_{c}{ }^{2}$, estimation of $\pi, \alpha$ and $B$ proceeds by ordinary least squares for the linear model. The estimated treatment mean adjusting for competition effect is obtained by subtracting $2 \beta$ from the unadjusted mean.

An alternative model in which to investigate the effect of competition between plots on the mean yield of two neighbouring plots is

$$
y=B \pi+T \alpha+X \delta+\tau
$$

where $X$ is an n-vector of the mean yield of neighbouring plots and is calculated by $X=R y$,

$\boldsymbol{\delta}$ is a common competition coefficient, and all other terms were defined in equation (1a).

The parameters and the treatment mean can be estimated by an analysis of covariance. The estimated covariate regression coefficient can be interpreted as the competition coefficient. 
$\begin{array}{ll}\text { Let } & \Gamma=\left|\begin{array}{l}\pi \\ \alpha \\ B\end{array}\right|, \quad D=B / T / R T \text { for model (1a) } \\ \text { or } \quad \Gamma=\left|\begin{array}{l}\pi \\ \alpha\end{array}\right|, \quad D=B / T / X \text { for model (1b) }\end{array}$

Then, we can rewrite (1a) or (1b) as

$$
y=D \Gamma+\tau
$$

In taking into account the local variation in soil fertility, the method extends immediately to incorporate trend effects by following the residual maximum likelihood neighbour analysis of Gleeson and Cullis (1987). Thus a neighbour model for incorporating both trend effect and interplot competition can be written as

$$
y=D \Gamma+\varepsilon+\cap
$$

where $y, D$ and $\Gamma$ are defined above, $\varepsilon$ is an $n$-vector of trend effects, and $\cap$ is an $n$-vector of measurement error, assumed to be independent $N\left(0, \sigma^{2}\right)$ deviates.

The elements of $\varepsilon$ are assumed to be represented by an $\operatorname{ARIMA}(p, d, q)$, where $\operatorname{ARIMA}(p, d, q)$ denotes a model for a random process whose $d^{\text {th }}$ differences follow an autoregressive order $p$ with moving average order $q$ process. 
The model for the differenced data can be written as

$$
\Delta y=\Delta D \Gamma+\Delta \varepsilon+\Delta h
$$

where $\Delta$ is an $(n-d) x n$ matrix specifying the form of differencing.

Assume the expectation of the differenced trend is zero, i.e. $E(\Delta \varepsilon)=0$. After differencing, the variance of $\Delta \varepsilon$ is locally constant,

$$
V(\Delta \varepsilon)=\sigma_{t}^{2} V(\Theta)
$$

where $\sigma_{t}{ }^{2}$ is the variance of $\Delta \varepsilon$ and $V(\Theta)$ is a matrix of correlation coefficients.

Further assume that the $\Delta \varepsilon$ are independent of $\cap$. Then the expectation and variance of the differenced data are

$$
E(\Delta y)=\Delta D \Gamma
$$

and

$$
V(\Delta y)=\sigma^{2} H
$$

respectively, where $H=\sigma_{t}^{2} / \sigma^{2} V(\Theta)+\Delta \Delta^{\prime}$.

The variance parameters to be estimated are $\sigma^{2}, \sigma_{t}{ }^{2}$ and $\Theta$. Residual maximum likelihood (REML) estimation is used to estimate the variance parameters and the REML estimate of the 
treatment effects is the weighted least squares estimate obtained by substituting the REML estimates for $\sigma_{t}{ }^{2} / \sigma^{2}$ and $\Theta$. The estimation can be carried out iteratively by the method given by Gleeson and Cullis (1987). The standard error of mean differences (SED) and the estimated trend effects are calculated using the REML estimate of $H$.

It is necessary to decide which of various choices of $p, d$ and $q$ will provide an adequate description of the random trend. The diagnostic test proposed by Ljung (1986) is used for model selection by investigating the effect of model misspecification on estimation of treatment effects and variance parameters. By simulation studies, Martin (1986), Besag and Kempton (1986), Gleeson and Cullis (1987) and Lill et al. (1988) suggest that for field trials, a low order $\operatorname{ARIMA}(p, d, q)$ model, with $p=0$ or $1, d=1$ or 2 and $q=0$ will generally provide an adequate fit.

\section{Example}

The data sets from field bean experiments provided by Kempton and Lockwood (1984) and the Australian Interstate Wheat Variety Trials, Series 19.2 in 1989 are used to illustrate these models.

For the field bean experiments, the aim was to assess the yield potential of six varieties and to investigate the possibility of interference among these varieties. The design 
consisted of four repeats of a balanced linear arrangement of 36 plots, with ends bordered, in which all varieties occurred both as left- and right-hand neighbours of each other exactly once. The trial was grown with a single row, $3 \mathrm{~m}$ long with 50 cm spacing between rows and no gap between plots. The field layout and yield (g/row) are shown in Table 1.

For the wheat experiments, the 16 trials had 26 varieties with 3 or 4 replicates. Each trial was laid out as a randomized complete block design with 28 plots in each block including an additional treated plot at each end.

The data for both the field bean and wheat experiments were analyzed assuming a randomized complete block design (RCBD), Besag and Kempton's method of adjustment for interference between neighbouring treatments ( $B K C)$, the method of using the mean yield of two neighbouring plots for adjustment for interplot competition (MNC), residual maximum likelihood neighbour analysis for adjusting for interplot competition with both the BKC technique (RBKC) and the MNC technique (RMNC), and residual maximum likelihood neighbour analysis (REML). The RBKC, RMNC and REML methods were fitted assuming an $\operatorname{ARIMA}(0,1,0)$ with $\Theta=0$.

The summary results of the RCBD, BKC, MNC, RBKC, RMNC and REML analyses of yield for the bean experiment are presented in Table 2. Every method gave highly significant differences between treatments. The significance of the $\mathrm{F}$ test for the 
competition effect in the analysis of variance for the model incorporating this indicates that a competition effect does exist. However, the BKC model gave no significant competition effect. This may be caused by the trend effect indicated by the significance of residual lag 1 autocorrelation. The estimated competition effect for BKC and RBKC, and competition coefficient for MNC and RMNC are also presented (Table 2). The subsequent adjustment to treatment means and their ranking (Table 2) indicates that there were some differences in the adjustment made by the various methods. The BKC and RBKC gave the same ranking of estimated treatment means but it was different to the one obtained by the other methods, i.e., MNC, RMNC, RCBD and REML.

In comparing error mean squares (EMS) and mean standard error of differences (SED) among the methods, the BKC and MNC gave smaller EMS than the RCBD but gave mean SED not appreciatively different while RBKC, RMNC and REML gave the smaller EMS and mean SED. There was no appreciable difference in efficiency of treatment contrasts between the BKC and MNC methods, and among RBKC, RMNC and REML methods. However, the RMNC method gave inadequate description of the trend indicated by the significant of the residual lag 1 autocorrelation.

The procedure of adjustment for interplot competition by the BKC method is extremely cumbersome and requires a large amount of computer memory which may be not available if there are a large number of treatments. The results of the bean 
experiment showed that there was no appreciable difference in mean SED between BKC and MNC, and between RBKC and RMNC methods. Therefore, only the MNC and RMNC analysis are considered for adjusting for interplot competition and neighbour effects in the wheat trials.

The summary results for the Interstate Wheat Variety Trials are presented in Table 3. The significance of the estimated competition coefficient for the MNC method for every site except Biloela indicates that competition effects exist. At Biloela a possible reason for the non-significant competition effect is the existing trend effect indicated by the significance of residual lagl and lag2 autocorrelations in the model. However, other sites, e.q. Cungena, Narrabri and Wellcamp, do have both significant residual lag1 and lag2 autocorrelations as well as significant competition coefficient. After taking into account the trend effect, the RMNC method gave significant competition effects at every site except Dooen and Kapinnie. There the non-significance of the $X$ estimated competition coefficient appears to be caused by an inadequate description of the trend using the RMNC method and no significant trend effect using the MNC method.

The plots of the deviation of ranking of estimated treatment means for MNC, RMNC and REML methods from that obtained for the RCBD method (Fig.1) illustrate the difference or change in ranking obtained from the various methods. If there is no different or change in ranking the points would lie on the 
zero line. The scatter plots (Fig.1) indicate that there are some changes in the ranking of the treatment means. For the MNC method, there is a large change in ranking of estimated treatment means at Cungena and Drillham which have a large competition coefficient. When the absolute size of the estimated competition coefficient is decreased, such as at Canberra, Trayning and Wagga, the change in ranking is also decreased. Thus the degree of change in ranking seems to depend on the size of the estimated competition coefficient. A similar interpretation of the deviation of the change in ranking of the estimated treatment means for the RMNC method from that obtained for the REML method (Fig.2) can be inferred.

In comparing EMS and mean SED among the methods, the MNC method gave an EMS and mean SED smaller than or equal to that of the RCBD method. The significance of the lag1 or lag2 autocorrelations in the RCBD model for every site indicates the existence of a trend, except for Canberra and Yanco. When also taking into account the association between plots, the REML method gave EMS and mean SED not appreciatively different from those from the RMNC method. For the comparison between the RMNC and MNC methods the result depended on the significance of the trend and competition effects. If the RMNC model gave an adequate description of trend and the MNC model showed significance of the association of neighbouring plots, then the RMNC method gave a smaller EMS and mean SED than the MNC method. However, when the MNC model gave no 
significant association of neighbouring plots or the RMNC model gave an inadequate description of the trend, the RMNC did not necessarily decrease the EMS or mean SED.

\section{Discussion}

The model for incorporating trend effect and interplot competition has been applied to a small bean data set and several larger wheat sets. However, the effect of two different methods of defining interplot competition has been investigated only for the bean data. It is clear that the addition of a term for competition effects into the conventional model can improve the efficiency of estimation of treatment contrasts. The ranking of estimated treatment means obtained from the various ways of defining interplot competition in the model may or may not differ. When the mean of neighbouring plots was used to assess competition effect, there was some change in the estimated treatment means and their ranking compared with RCBD. The degree of change depended on the significance and size of the estimated competition coefficient. After taking into account the trend effect, the RMNC model assuming an $\operatorname{ARIMA}(0,1,0)$ with $\Theta=0$ trend was more efficient in estimating the EMS and mean SED than the MNC model, but it was not significantly different from the REML model. However, the estimated treatment means and their ranking obtained from the RMNC and REML model were different. The significance of both the competition and trend effects are 
important indexes in assessing the usefulness of the RMNC method.

The incorporation of both trend and competition into the model has been shown to be sensitive to differences in the way interplot competition is assessed. More work is need to determine the most appropriate method of defining interplot competition and the specification of a test for the existence of competition effects.

\section{References}

AUSTIN, R. B. and BLACKWELL, R. D. (1980). Edge and neighbour effects in cereal yield trials. J. Agricult. Sci. 94, 731-734.

BESAG, J. and KEMPTON, R. (1986). Statistical analysis of field experiments using neighbouring plots. Biometrics 42, $231-251$.

BOX, G. E. P. and PIERCE, D. A. (1970). Distribution of residual autocorrelations in autoregressive integrated moving average time series model. J. Ann. Statist. Assoc. $65,1509-1526$.

CANNELL, M. G. R., NJUGUNA, C. K., FORD, E. D., SMITH, R. and ROSS-PARKER, H. M. (1977) .Variation in yield among competing individual within mixed genotype stands of tea: a selection problem. J. App. Ecol. 14, 969-985. DRAPER, N. R. and GUTTMAN, I. (1980). Incorporating overlap effects from neighbouring units into response surface 
models. App. Statist. 29, 128-134.

FEDERER, W. T. and BASFORD, K. E. (1990). Competing effects

designs and models for two-dimensional field arrangements. Biometrics (to appear).

GLEESON, A. C. and CULLIS, B. R. (1987). Residual maximum

likelihood (REML) estimation of a neighbour model for field experiments. Biometrics 43, 277-288.

GOMEZ, K. A. (1972). Border effects in rice experimental plots II. Varietal competition. Exptl. Agricult. 8, 295-298. GREEN, P. J., JENNISON, C., and SEHEULT, A. H. (1985). Analysis of field experiments by least squares smoothing. J. R. Statist. Soc. B 47, 299-315.

JENSON, N. F. and FEDERER, W. T. (1964). Adjacent row competition in wheat. Crop. Sci. 4, 641-645.

KEMPTON, R. A. (1982). Adjustment for competition between varieties in plant breeding trials. J. Agricult. Sci. 98, $599-611$.

KEMPTON, R. A. and LOCKWOOD, G. (1984). Interplot competition in variety trials of fields beans (Viciafaba L.). J. Agricult. Sci. 103, 293-302.

LILL, W. J., GLEESON, A. C., and CULlis, B. R. (1988).

Relative accuracy of a neighbour model for field experiments. J. Agricult. Sci. 111, 39-346.

LJUNG, G. M. (1986). Diagnostic testing of univariate time series model. Biometrika 73, 725-730.

MARTIN, R. J. (1986). On the design of experiments under spatial correlation. Biometrika 73, 247-277.

MEAD, R. (1967). A mathematical model for the estimation of 
interplant competition. Biometrics 23, 189-205.

PATTERSON, H. D. and HUNTER, E. A. (1983). The efficiency of incomplete block designs in National List and Recommended List cereal variety trial, J. Agricult. Sci. 101, 427-433. PEARCE, S. C. (1957). Experimenting with organisms as blocks. Biometrika 44, 141-149.

WILKINSON, G. N., ECKERT, S. R., HANCOCK, T. W., and Mayo, 0. (1983). Nearest-neighbour (NN) analysis of field experiments (with Discussion). J. R. Statist. Soc. B 45, $151-211$.

WILLIAMS, E. R. (1986). A neighbour model for field experiments. Biometrika 73, 279-287. 
'able 1. Field layout and corresponding yield (g/row) of single-row plot from bean trial adopted from Kempton and Lockwood (1984)

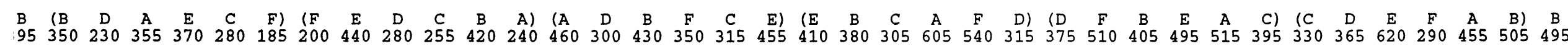

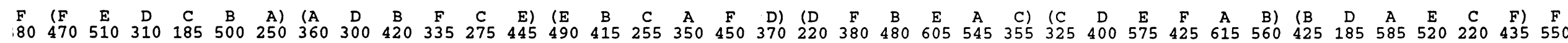

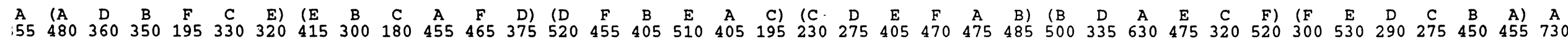

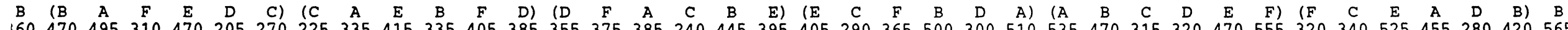
160470495310470205270225335415335405385355375385240445395405290365500300510535470315320470555320340525455280420565 
Table 2. Summary table for yield analysis of bean experiment

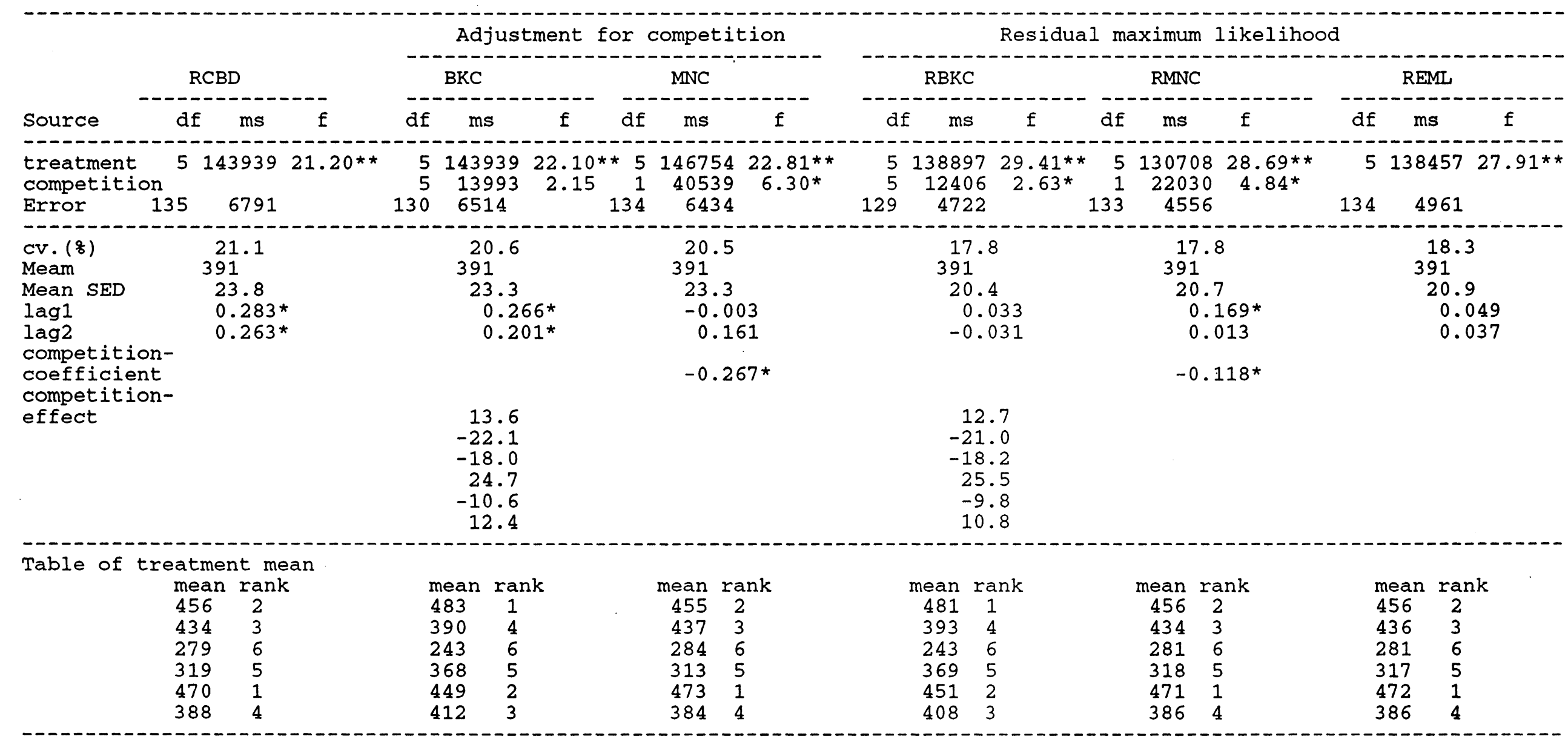

Note * significant at $5 \%$ level

* * significant at $1 \%$ level 
Table 3. Summary table for yield analyses of wheat trials

\begin{tabular}{|c|c|c|c|c|c|c|c|}
\hline Site & Model & $\operatorname{lag} 1$ & $\operatorname{lag} 2 \mathrm{co}$ & $\begin{array}{l}\text { petition } \\
\text { Eficient }\end{array}$ & EMS & Mean & SED \\
\hline BILOELA & $\begin{array}{l}\text { RCBD } \\
\text { MNC } \\
\text { RMNC } \\
\text { REML }\end{array}$ & $\begin{array}{l}0.46^{\star} \\
0.32^{\star} \\
0.23 \\
0.16\end{array}$ & $\begin{array}{l}0.32^{*} \\
0.33^{*} \\
0.08 \\
0.06\end{array}$ & $\begin{array}{l}0.27 \\
-0.05 * \star\end{array}$ & $\begin{array}{l}0.31 \\
0.27 \\
0.02 \\
0.02\end{array}$ & $\begin{array}{l}7.17 \\
7.17 \\
7.17 \\
7.17\end{array}$ & $\begin{array}{l}0.46 \\
0.44 \\
0.27 \\
0.26\end{array}$ \\
\hline CANBERRA & $\begin{array}{l}\text { RCBD } \\
\text { MNC } \\
\text { RMNC } \\
\text { REML }\end{array}$ & $\begin{array}{l}0.15 \\
0.15 \\
0.13 \\
0.14\end{array}$ & $\begin{array}{l}-0.26 \\
-0.11 \\
-0.14 \\
-0.28\end{array}$ & $\begin{array}{l}-0.22 * \star \\
-0.23 * \star\end{array}$ & $\begin{array}{l}0.53 \\
0.46 \\
0.42 \\
0.52\end{array}$ & $\begin{array}{l}7.10 \\
7.10 \\
7.10 \\
7.10\end{array}$ & $\begin{array}{l}0.51 \\
0.48 \\
0.48 \\
0.52\end{array}$ \\
\hline CUNGENA & $\begin{array}{l}\text { RCBD } \\
\text { MNC } \\
\text { RMNC } \\
\text { REML }\end{array}$ & $\begin{array}{l}0.47 * \\
0.30 * \\
-0.09 \\
-0.03\end{array}$ & $\begin{array}{l}0.34^{\star} \\
0.31^{\star} \\
-0.02 \\
-0.12\end{array}$ & $\begin{array}{r}0.65 * * \\
-0.03 * *\end{array}$ & $\begin{array}{l}0.18 \\
0.10 \\
0.01 \\
0.01\end{array}$ & $\begin{array}{l}2.86 \\
2.86 \\
2.86 \\
2.86\end{array}$ & $\begin{array}{l}0.30 \\
0.23 \\
0.13 \\
0.13\end{array}$ \\
\hline DRILLHAM & $\begin{array}{l}\text { RCBD } \\
\text { MNC } \\
\text { RMNC } \\
\text { REML }\end{array}$ & $\begin{array}{l}0.42^{\star} \\
-0.13 \\
-0.13 \\
-0.09\end{array}$ & $\begin{array}{l}0.22^{\star} \\
0.25^{\star} \\
0.25^{\star} \\
0.08\end{array}$ & $\begin{array}{l}0.68 * * \\
0.68 * *\end{array}$ & $\begin{array}{l}0.12 \\
0.07 \\
0.07 \\
0.00\end{array}$ & $\begin{array}{l}4.37 \\
4.37 \\
4.37 \\
4.37\end{array}$ & $\begin{array}{l}0.24 \\
0.18 \\
0.18 \\
0.15\end{array}$ \\
\hline DOOEN & $\begin{array}{l}\text { RCBD } \\
\text { MNC } \\
\text { RMNC } \\
\text { REML }\end{array}$ & $\begin{array}{l}0.28^{*} \\
0.34^{*} \\
0.33^{*} \\
0.17\end{array}$ & $\begin{array}{l}0.13 \\
0.20 \\
0.14 \\
0.05\end{array}$ & $\begin{array}{l}0.30 * \star \\
0.20\end{array}$ & $\begin{array}{l}1.33 \\
1.25 \\
1.04 \\
0.96\end{array}$ & $\begin{array}{l}8.50 \\
8.50 \\
8.50 \\
8.50\end{array}$ & $\begin{array}{l}0.82 \\
0.80 \\
0.77 \\
0.76\end{array}$ \\
\hline KAPINNIE & $\begin{array}{l}\text { RCBD } \\
\text { MNC } \\
\text { RMNC } \\
\text { REML }\end{array}$ & $\begin{array}{r}0.10 \\
-0.19 \\
-0.17 \\
-0.02\end{array}$ & $\begin{array}{l}0.27 \text { * } \\
0.15 \\
0.11 \\
0.06\end{array}$ & $\begin{array}{l}0.27 \text { * } \\
0.21\end{array}$ & $\begin{array}{l}0.43 \\
0.39 \\
0.35 \\
0.26\end{array}$ & $\begin{array}{l}9.00 \\
9.00 \\
9.00 \\
9.00\end{array}$ & $\begin{array}{l}0.46 \\
0.44 \\
0.44 \\
0.42\end{array}$ \\
\hline MERREDIN & $\begin{array}{l}\text { RCBD } \\
\text { MNC } \\
\text { RMNC } \\
\text { REML }\end{array}$ & $\begin{array}{r}0.20 \\
-0.36 \\
-0.26 \\
-0.25\end{array}$ & $\begin{array}{l}0.40^{*} \\
0.32 * \\
0.05 \\
0.12\end{array}$ & $\begin{array}{r}0.42 * \star \\
-0.28 * \star\end{array}$ & $\begin{array}{l}0.10 \\
0.08 \\
0.02 \\
0.04\end{array}$ & $\begin{array}{l}2.99 \\
2.99 \\
2.99 \\
2.99\end{array}$ & $\begin{array}{l}0.22 \\
0.20 \\
0.15 \\
0.16\end{array}$ \\
\hline NARRABRI & $\begin{array}{l}\text { RCBD } \\
\text { MNC } \\
\text { RMNC } \\
\text { REML }\end{array}$ & $\begin{array}{l}0.61 * \\
0.29 * \\
0.02 \\
0.01\end{array}$ & $\begin{array}{l}0.61 * \\
0.53^{\star} \\
0.17 \\
0.25^{\star}\end{array}$ & $\begin{array}{r}0.46^{\star *} \\
-0.28 *\end{array}$ & $\begin{array}{l}1.05 \\
0.82 \\
0.05 \\
0.20\end{array}$ & $\begin{array}{l}6.28 \\
6.28 \\
6.28 \\
6.28\end{array}$ & $\begin{array}{l}0.72 \\
0.64 \\
0.40 \\
0.45\end{array}$ \\
\hline TRAYNING & $\begin{array}{l}\text { RCBD } \\
\text { MNC } \\
\text { RMNC } \\
\text { REML }\end{array}$ & $\begin{array}{l}-0.25 \\
-0.12 \\
-0.12 \\
-0.25\end{array}$ & $\begin{array}{l}0.35^{\star} \\
0.29 * \\
0.29 * \\
0.35^{*}\end{array}$ & $\begin{array}{l}-0.19 * \star \\
-0.19 *\end{array}$ & $\begin{array}{l}0.05 \\
0.04 \\
0.04 \\
0.05\end{array}$ & $\begin{array}{l}2.43 \\
2.43 \\
2.43 \\
2.43\end{array}$ & $\begin{array}{l}0.15 \\
0.15 \\
0.15 \\
0.16\end{array}$ \\
\hline TURRET & $\begin{array}{l}\text { RCBD } \\
\text { MNC } \\
\text { RMNC } \\
\text { REMI }\end{array}$ & $\begin{array}{c}0.24^{\star} \\
-0.30 \\
-0.34 \\
0.02\end{array}$ & $\begin{array}{r}0.22^{\star} \\
0.25^{\star} \\
0.17 \\
-0.08\end{array}$ & $\begin{array}{l}0.62 \star * \\
0.52 \text { ** }\end{array}$ & $\begin{array}{l}0.70 \\
0.42 \\
0.36 \\
0.25\end{array}$ & $\begin{array}{l}6.35 \\
6.35 \\
6.35 \\
6.35\end{array}$ & $\begin{array}{l}0.59 \\
0.46 \\
0.45 \\
0.44\end{array}$ \\
\hline
\end{tabular}


Table 3. continued

\begin{tabular}{|c|c|c|c|c|c|c|c|}
\hline Site & Model & $\operatorname{lag} 1$ & $\operatorname{lag} 2$ & $\begin{array}{l}\text { competition } \\
\text { coefficient }\end{array}$ & EMS & Mean & SED \\
\hline URANIA & $\begin{array}{l}\text { RCBD } \\
\text { MNC } \\
\text { RMNC } \\
\text { REML }\end{array}$ & $\begin{array}{r}0.20 \\
0.08 \\
-0.09 \\
-0.10\end{array}$ & $\begin{array}{l}0.33 \text { * } \\
0.31 \text { * } \\
0.07 \\
0.06\end{array}$ & $\begin{array}{r}0.22 * \star \\
-0.09 * \star\end{array}$ & $\begin{array}{l}0.16 \\
0.15 \\
0.05 \\
0.06\end{array}$ & $\begin{array}{l}7.20 \\
7.20 \\
7.20 \\
7.20\end{array}$ & $\begin{array}{l}0.28 \\
0.28 \\
0.22 \\
0.22\end{array}$ \\
\hline WAGGA & $\begin{array}{l}\text { RCBD } \\
\text { MNC } \\
\text { RMNC } \\
\text { REML }\end{array}$ & $\begin{array}{r}0.41^{\star} \\
0.35^{\star} \\
-0.00 \\
0.10\end{array}$ & $\begin{array}{r}0.15 \\
0.13 \\
0.02 \\
-0.00\end{array}$ & $\begin{array}{r}0.11 * \star \\
-0.09 * \star\end{array}$ & $\begin{array}{l}0.61 \\
0.60 \\
0.26 \\
0.30\end{array}$ & $\begin{array}{l}8.00 \\
8.00 \\
8.00 \\
8.00\end{array}$ & $\begin{array}{l}0.64 \\
0.64 \\
0.51 \\
0.52\end{array}$ \\
\hline WALPEUP & $\begin{array}{l}\text { RCBD } \\
\text { MNC } \\
\text { RMNC } \\
\text { REML }\end{array}$ & $\begin{array}{c}0.34 * \\
0.15 \\
-0.03 \\
0.04\end{array}$ & $\begin{array}{r}0.15 \\
0.08 \\
-0.10 \\
-0.20\end{array}$ & $\begin{array}{l}0.42 * * \\
0.21 * *\end{array}$ & $\begin{array}{l}0.18 \\
0.14 \\
0.03 \\
0.00\end{array}$ & $\begin{array}{l}5.10 \\
5.10 \\
5.10 \\
5.10\end{array}$ & $\begin{array}{l}0.30 \\
0.27 \\
0.22 \\
0.19\end{array}$ \\
\hline WELLCAMP & $\begin{array}{l}\text { RCBD } \\
\text { MNC } \\
\text { RMNC } \\
\text { REML }\end{array}$ & $\begin{array}{c}0.45^{\star} \\
0.37^{\star} \\
0.14 \\
-0.01\end{array}$ & $\begin{array}{l}0.44 \text { * } \\
0.43 \text { * } \\
0.08 \\
0.07\end{array}$ & $\begin{array}{r}0.30 * * \\
-0.08 * *\end{array}$ & $\begin{array}{l}0.20 \\
0.18 \\
0.07 \\
0.08\end{array}$ & $\begin{array}{l}6.73 \\
6.73 \\
6.73 \\
6.73\end{array}$ & $\begin{array}{l}0.32 \\
0.30 \\
0.24 \\
0.24\end{array}$ \\
\hline WONGAN & $\begin{array}{l}\text { RCBD } \\
\text { MNC } \\
\text { RMNC } \\
\text { REML }\end{array}$ & $\begin{array}{l}0.73 \text { * } \\
0.08 \\
0.02 \\
0.06\end{array}$ & $\begin{array}{l}0.63 \text { * } \\
0.05 \\
0.02 \\
0.03\end{array}$ & $\begin{array}{l}0.76 * * \\
0.59 * *\end{array}$ & $\begin{array}{l}0.31 \\
0.08 \\
0.06 \\
0.01\end{array}$ & $\begin{array}{l}3.37 \\
3.37 \\
3.37 \\
3.37\end{array}$ & $\begin{array}{l}0.39 \\
0.20 \\
0.19 \\
0.16\end{array}$ \\
\hline YONCO & $\begin{array}{l}\text { RCBD } \\
\text { MNC } \\
\text { RMNC } \\
\text { REML }\end{array}$ & $\begin{array}{l}-0.21 \\
-0.26 \\
-0.27 \\
-0.33\end{array}$ & $\begin{array}{r}0.03 \\
-0.03 \\
-0.04 \\
0.02\end{array}$ & $\begin{array}{l}0.18 * \star \\
0.17^{* *}\end{array}$ & $\begin{array}{l}0.16 \\
0.14 \\
0.13 \\
0.08\end{array}$ & $\begin{array}{l}6.24 \\
6.24 \\
6.24 \\
6.24\end{array}$ & $\begin{array}{l}0.32 \\
0.30 \\
0.30 \\
0.28\end{array}$ \\
\hline
\end{tabular}

Note * significant at $5 \%$ level

** significant at 1 \& level 
Figure 1. Deviation of the ranking of estimated treatment means from the RCBD for the MNC, RMNC and REML models; $\triangle \mathrm{MNC}, \nabla$ RMNC, $\square$ REML; no symbol implies that the deviation for that treatment was exceeded the assigned interval.
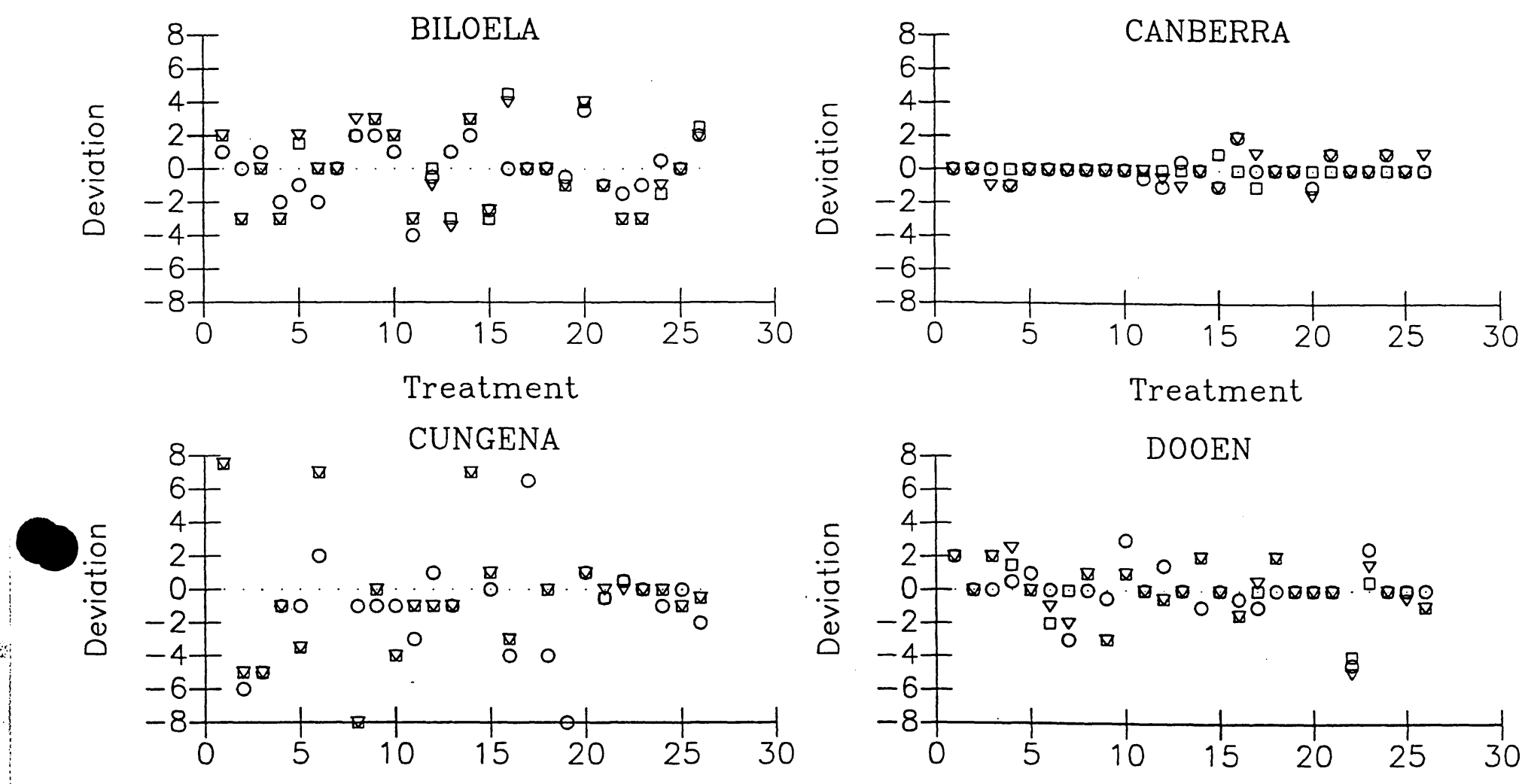

Treatment

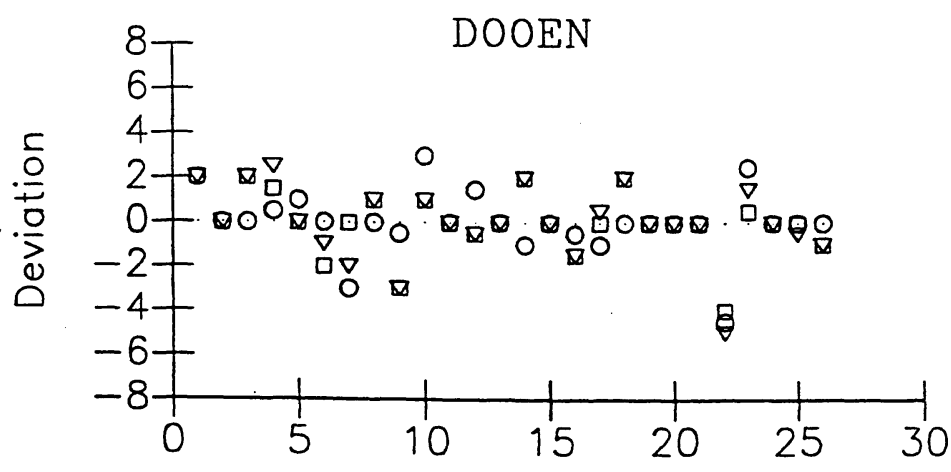

Treatment
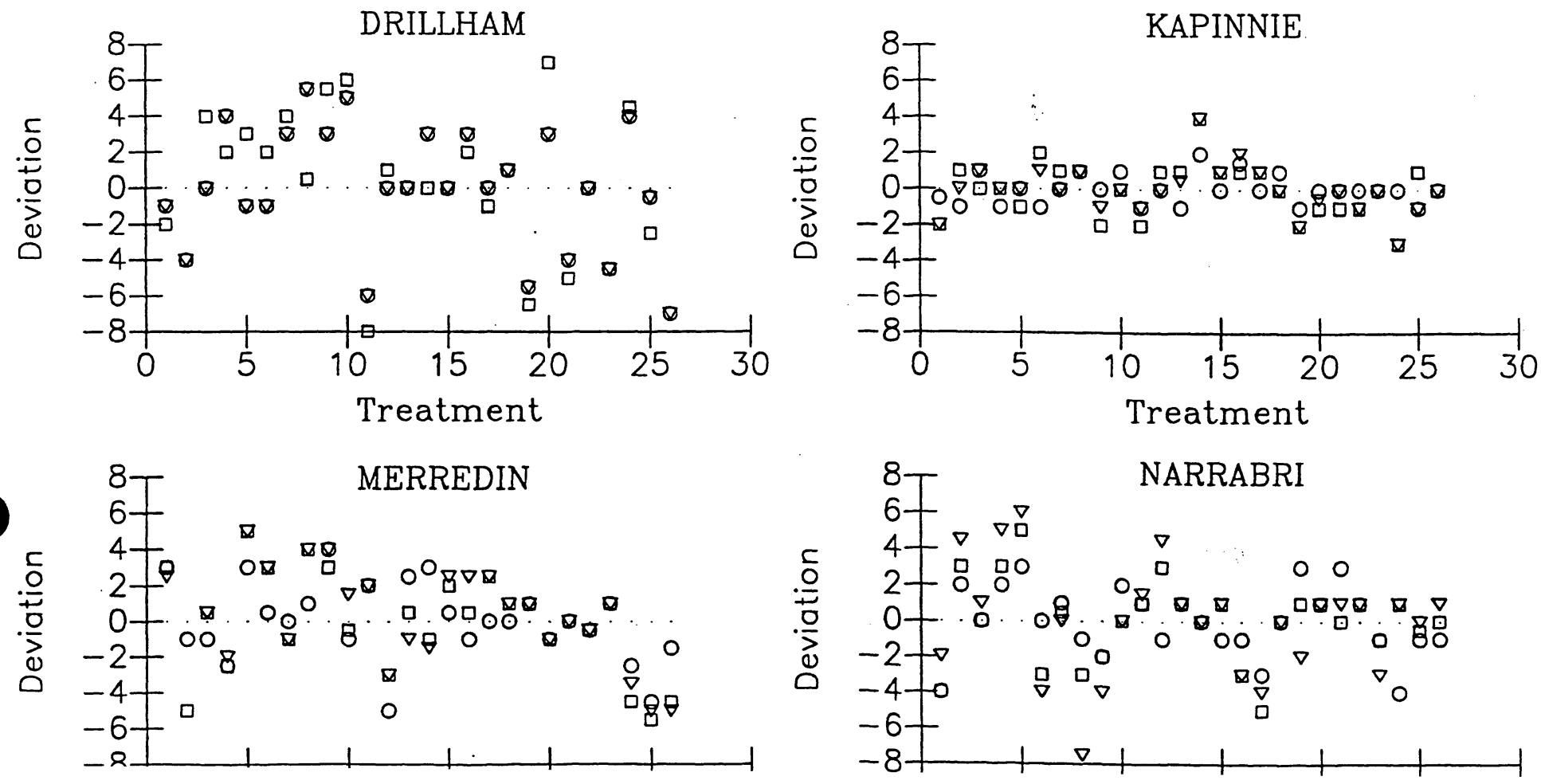


Figure 2. Deviation of the ranking of estimated treatment means from the RMNCL for the REML model.
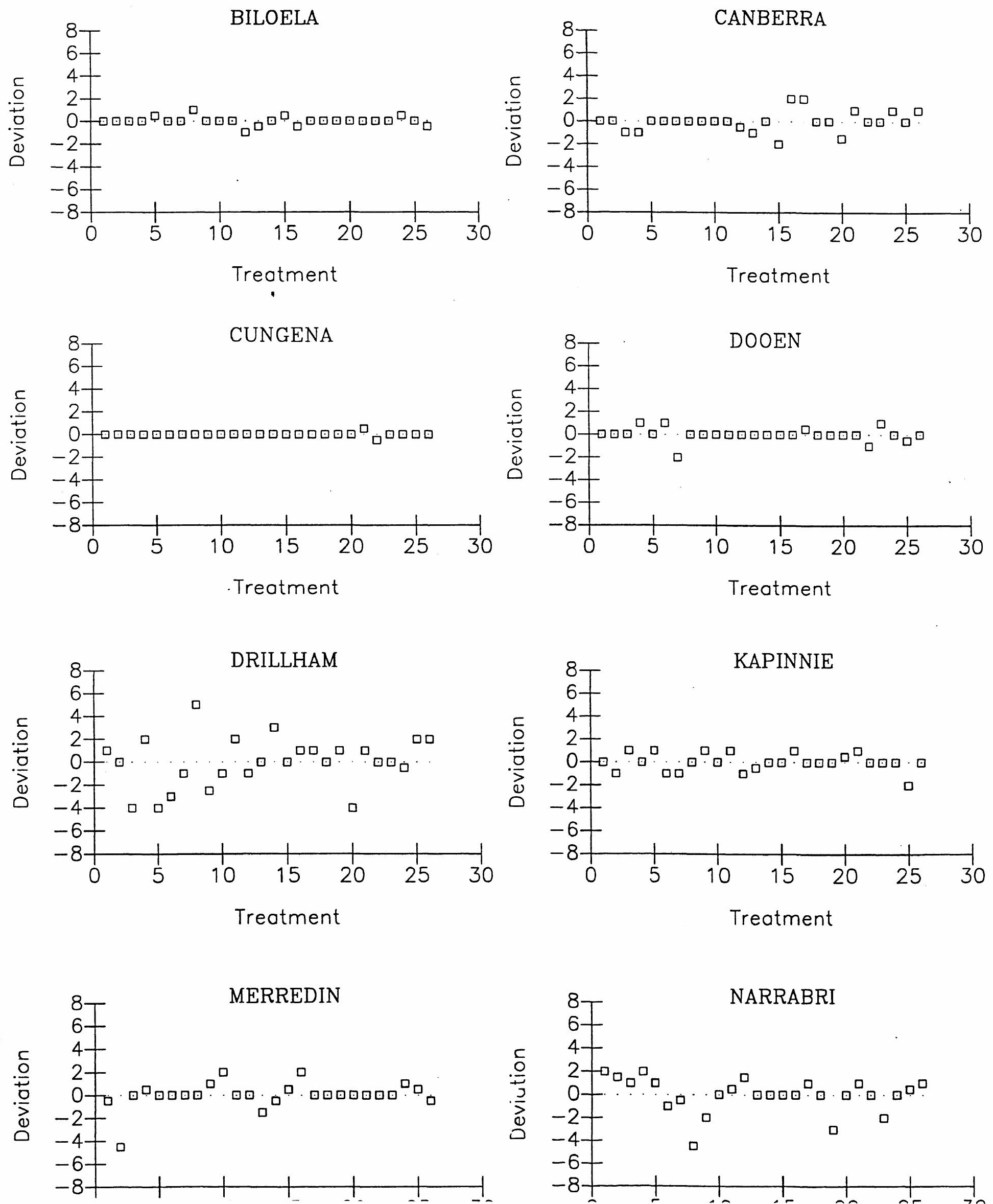

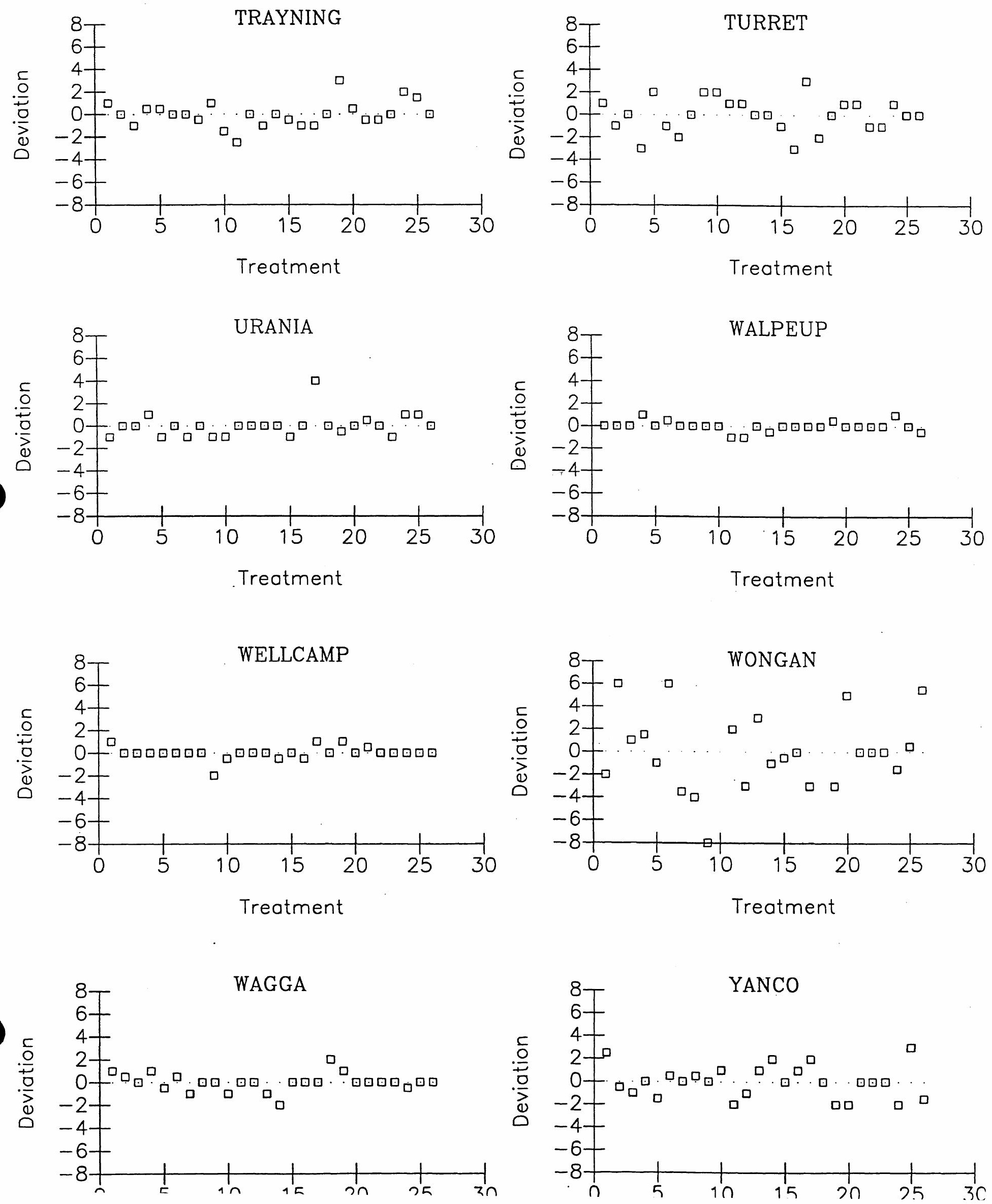